\title{
The Application of Micro-Lesson in Reform of Higher Vocational Education
}

\author{
Wenjing Cui ${ }^{1, a}$, Xinhe Xin ${ }^{2, b}$, Hongliang Wang ${ }^{1, c}$, Gentuya Meng ${ }^{1, d}$ and \\ Wei Hou ${ }^{1, e, *}$
}

\author{
${ }^{1}$ Department of Chemical Engineering, Inner Mongolia Vocation college of Chemical Engineering, \\ Hohhot, Inner Mongolia, 010070, China; \\ ${ }^{2}$ Department of Management Engineering, Inner Mongolia Vocation college of Chemical Engineering, \\ Hohhot, Inner Mongolia, 010070, China; \\ azczcwj@sina.com, b33550919@qq.com, c13848514517@139.com, dnhymgty@126.com, \\ enhyhw@126.com
}

Keywords: Micro-lesson, Reform, Vocational education.

\begin{abstract}
With the continuous development of information technology, the vocational education system need to further reform as the emergence of a series of micro things. Micro-lesson becomes a hot topic right now. The application of micro-lesson in college can improve the quality and level of modern leaching
\end{abstract}

\section{Introduction}

In recent years, the government pays more attention to higher vocational education, and the policies of vocational education have been constantly improvement. Colleges are required to make their own shortcomings changed, optimize recourses and create new teaching ways to adapt the national policy. In this context, the teaching reform of vocational education in college is imperative.

The aim of higher vocational education is to train the personnel with creativity and practice ability, however, the traditional teaching mode cannot stimulate the interests of students in learning. With the development of information technology and multimedia technology, people's life style has changed o lot. The internet technology promotes the application of multimedia teaching and the use of modern educational media. Micro-lesson is one of the product in this new area. It not only can active atmosphere of the classroom and break though the teaching different, but also improve the quality of teaching and learning.

\section{The definition and characteristic of micro-lesson}

\subsection{Definition and development of micro-lesson.}

Micro-lesson originated in 1993 in the United States in Northern Ireland, professor McGrew developed a one-minute long lesson of organic chemistry. In 1995, professor T.P.Kee in university of Leeds gave a one-minute long lecture. The concept of "micro-lesson" was first put forward by professor David Penrose abroad in 2008, while Tiesheng $\mathrm{Hu}$ gave the very first concept "micro-lesson" in 2011 in China. "Micro-lesson is to support reversal, blended learning, mobile learning, learning and other new fragmentation personalized teaching and learning methods and network approach to dapper mini streaming instructional videos as the main carrier, for a point or teaching knowledge and well-designed development of a situational, fun, visualization of digital learning resources, should also include topics related to teaching and teaching design, material, courseware and source files, reflective teaching, practice tests and feedback from students, teachers, teaching resources and other auxiliary reviews to carry out teaching and research network based on micro-lesson (including lessons, classes, observation and evaluation and share exchange), will become an important way to improve the internet age of information technology teaching ability of teachers and 
information and research capabilities, thus contributing to professional development of teachers." by Xiaojun Zheng in Guangxi Teacher College.

\subsection{Characteristics and advantages of micro-lesson.}

Micro-lesson is a kind of new teaching mode based on the combination of intelligent terminal and mobile internet. The typical characteristics and advantages of micro-lesson are given in Figure 1. Micro-lesson is mainly characterized by prominent theme, clear point, diverse resources, and real scenarios, easy to use, semi-structured, and easy to expand. It can not only meet students' individual learning needs, let students moving debris, personalized learning become reality, but also expand the resources of traditional classroom learning and make the ideal of teaching students in accordance with their aptitude as possible. Furthermore, the advantages of micro teaching contain short teaching time, less teaching content, smaller resource capacity, simple results, variety communication, and feedback timely, targeted strong and so on.

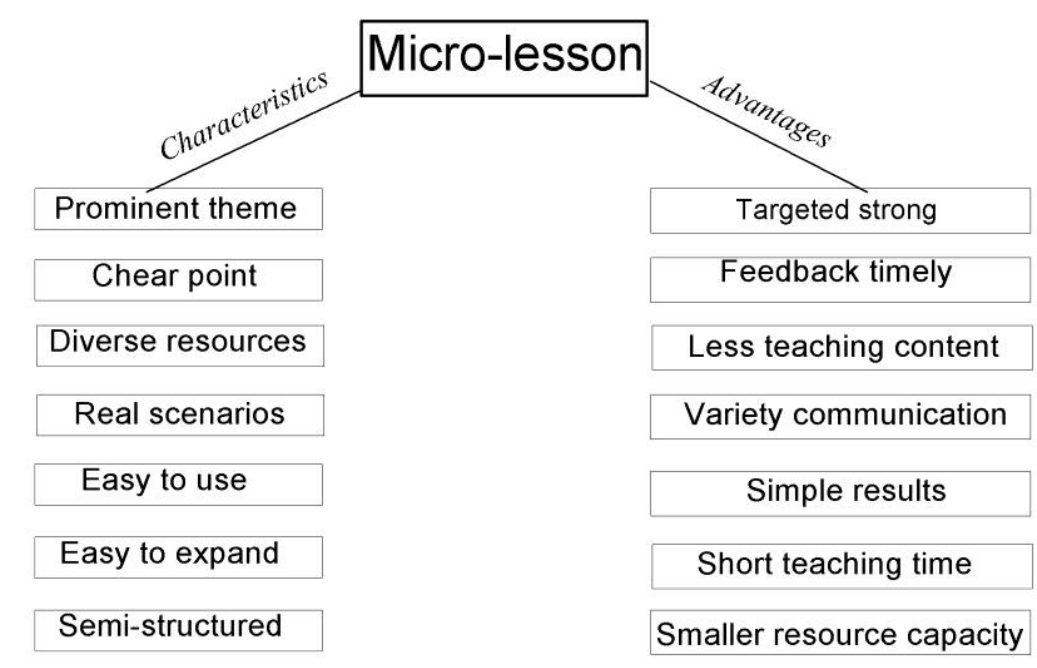

Fig. 1 The characteristics and advantages of micro-lesson

\section{Problems of traditional teaching}

\subsection{Lack of attractive.}

The traditional teaching is often conducted by one way lack of attractive and challenging teaching methods [1]. Teachers spend a lot of time writing on the blackboard while students are busy copying notes in the limited class time. Therefore, the teaching effect is not obvious.

\subsection{Boring teaching method.}

Traditional teaching limits the development of the students' way of thinking. Teachers are always at the high top, condescending. Students in the orderly classroom are ignored for the experience of process knowledge, and deprived of thinking time and space, and lack of challenge and innovation. In all, the traditionally drab way of teaching cannot effectively stimulate students' interest in autonomous learning and individualized learning.

\subsection{Limited students' ability.}

Traditional education is not conducive to the cultivation of students' ability. There is lack of appropriate communication between students and students, because traditional classroom teaching is always building activities between teachers and students. The students rarely help each other and lack cooperation consciousness with a relatively weak collective mind.

\subsection{Low teaching efficiency}

The teacher knows little about their students' daily learning condition and cannot give counseling in time $[3,4]$. Also, the students' learning materials are not adequate which will weaken the students' learning effect. Students fail to make full use of their fragmented time to learn. When waiting for the bus or during the breaks, students tend to waste their valuable time and play games, watch videos by mobile phone, tablets or mobile devices. 


\section{The application of micro-lesson in college education}

\subsection{Improving the students learning ability.}

College students have more spare time during the university, they can set up their own learning plan, so as to improve their learning ability. Micro-lesson is less content, smaller capacity, easy to accept, entertaining and random so that it improves the learning effect of the students. Furthermore, college students generally take the preview before class, learning in class and consolidating and expanding the knowledge after class through the way of micro class learning. Also, each student can learn at their own ability. Students with good grades learn more and more difficult courses than the low-mark ones.

\subsection{Increasing classroom interaction.}

Students always learn the knowledge after the class through micro-lesson. In the class, teachers have more than ever time to communicate with students face to face clearly. At the same time, interaction between students has also increased, teachers are busy to answer the question of some students, while the others can form their own cooperative groups, mutual learning between students.

\subsection{Making the classroom content diversity.}

The application of the micro-lesson may lead teachers to sharing of teaching resources. Enlarging the knowledge points of every micro-lesson can maximize the students' learning interest. Micro-lesson content is combined with the basic knowledge and the requirement of expanding knowledge. At the same time, enriching the class knowledge can reduce the single nature of the classroom contents, which can increase the diversity of classroom contents.

\section{The teaching mode of micro-lesson.}

The application of micro-lesson in higher vocational education may broke the inherent pattern of traditional education mode so as the teaching procedures.

There are three stages during the teaching procedure of the micro-lesson. Firstly, students use leisure time to watch the micro-lessons' video to autonomous learning and complete the preview tasks before the class. In this stage, students can ask questions online if they encountered problems. Teachers prepare their teaching plans based on the questions and the tasks that students completed. Secondly, during the class time, the communication between students and students is arranged after teachers giving a short lecture. And most of time of class, teacher mainly put forward some exploratory questions, then team collaboration with in-depth communication between students and teacher to explore the answers. A timely test is also carried out to see whether the students grasp the knowledge or not. Finally, students can review what they have learned in class at any time they want. The micro-lesson videos of inter-discipline courses as well as frontier subjects are also provided for the students who want to develop a deep breadth of learning. Besides students can learn autonomously after class to strengthen their thinking. It is of great significance to improve students' problem solving ability and cultivate their creative transcendental talents.

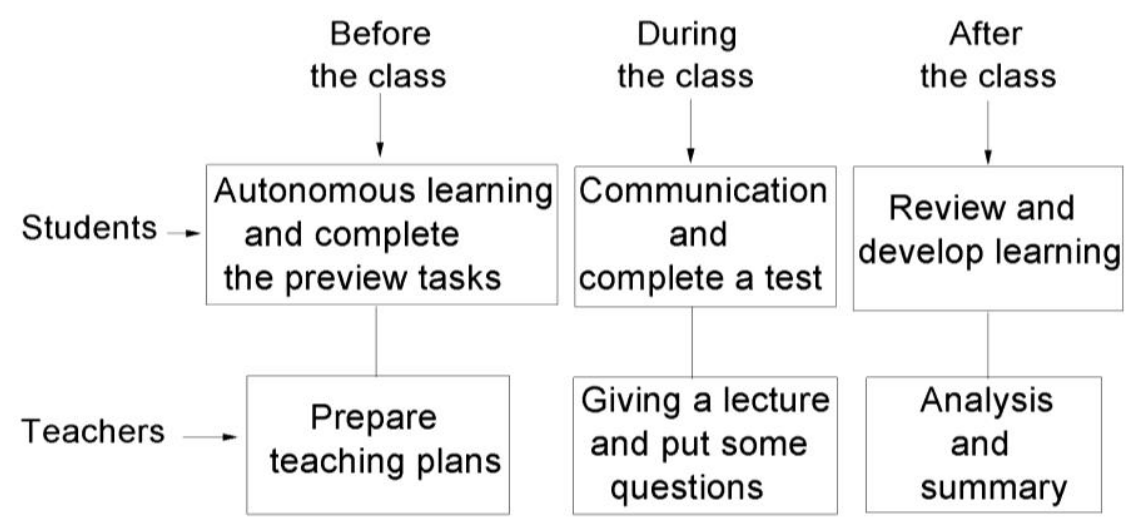

Fig. 2 The teaching procedure of micro-lesson 
In future, it requires lots of investment and time on micro-lesson production and resources integration. Developing micro-lesson into system needs top-level design, overall planning, teamwork, sharing the resources to achieve maximum benefit. 5-8-minute lesson must be ultimate in quality, therefore, the role of teacher is reshaping. It will be capable of operating theory of "double" teacher that is not only to be a student mentor, but also to become micro-lesson production director.

\section{Summary}

The world has entered the Internet time. The era of big data, along with the emergence of a series of micro things, such as micro blog, micro-letter, microfilm, is changing the way of people live. This will naturally promote vocational education reform, and micro-lesson has important application value in college teaching. Micro-lesson applied leaning activities, so that students get the full autonomy of learning and teachers' teaching practice activities are also improved. In future, the applications of micro-lesson teaching still have a lot of discuss research issues.

\section{References}

[1]. G.J.Gao. To create a new class in micro class - analysis on the efficient information technology based on the micro class concept. Education. Vol. 12 (2014) p. 28-30.

[2]. G.Zhang. The application of micro lesson in college Chinese teaching. $3^{\text {rd }}$ International Conference on Education, Management, Arts, Economics and Social Science. 2015, p. 419-423.

[3]. J. Shu. Try Flipping Classroom Based on Micro Lesson in Chinese Course of Vocational Schools. 4th International Conference on Social Sciences and Society. 2015, p. 209-214.

[4]. Y.Jin. Micro Class Application and Exploration in Japanese Teaching. International Conference on Economics, Social Science, Arts, Education and Management Engineering. 2015, p. 183-185.

[5]. Y.Wu, G. Xu, Z.Qu. On the Interactive Teaching Mode_A Micro Course to an Introduction to Database System. International Conference on Education Research and Reform. 2015, p. 29-34. 